\title{
Correction to: Latent profiles of attitudes toward print and digital reading among adolescents
}

\section{Bong Gee Jang ${ }^{1} \cdot$ Ji Hoon Ryoo ${ }^{2} \cdot$ Kristin Conradi Smith ${ }^{3}$}

Published online: 11 January 2021

(c) Springer Nature B.V. 2021

\section{Correction to: Reading and Writing https://doi.org/10.1007/s11145-020-10104-7}

In the original publication, the article title was incorrectly published. The correct title has been given with this Correction.

The original article has been corrected.

Publisher's Note Springer Nature remains neutral with regard to jurisdictional claims in published maps and institutional affiliations.

The original article can be found online at https://doi.org/10.1007/s11145-020-10104-7.

Ji Hoon Ryoo

ryoox001@yonsei.ac.kr

Bong Gee Jang

bojang@syr.edu

Kristin Conradi Smith

keconradi@wm.edu

1 Department of Reading and Language Arts, Syracuse University, 202 Huntington Hall, Syracuse, NY 13244, USA

2 Department of Education, School of Education, Yonsei University, 512 Educational Science Building, 50 Yonsei-Ro, Seodaemoon-Gu, Seoul 03722, South Korea

3 Department of Curriculum and Instruction, William and Mary, 301 Monticello Avenue, Williamsburg, VA 23185, USA 